\title{
POR UMA ANTROPOLOGIA BENJAMINIANA: REPENSANDO PARADIGMAS DO TEATRO DRAMÁTICO*
}

John C. Dawsey

\begin{abstract}
De acordo com a versão de Turner, o curandeiro usa o ritual para criar tensão narrativa e catarse dramática para fechar uma ferida aberta no corpo social, reproduzindo assim a estrutura social tradicional — numa demonstração verdadeiramente catártica e fulminante do que Brecht chamaria de teatro dramático (aristotélico). Em oposição a essa espécie de teatro, Brecht desenvolvia, enquanto artista revolucionário comunista, uma forma épica de tragédia para tentar curar a ferida aberta da estrutura social capitalista no século 20 (Taussig 1992:150, tradução minha).
\end{abstract}

Nos remoinhos dos estudos de Michael Taussig, busco uma composição teórica, em contraponto: Walter Benjamin, Bertolt Brecht, Victor Turner e Clifford Geertz. ${ }^{1}$ Seria possível também enunciar no título um termo composto: "Por uma antropologia brecht-benjaminiana". Mas prefiro ressaltar, com o termo mais simples, a especificidade da leitura que aqui se faz — inclusive do teatro épico - sob o signo de Benjamin.

O ensaio não deixa de se apresentar como uma espécie de canteiro de obras benjaminiano. A justaposição de figuras aparentemente distantes da antropologia, do teatro e da crítica literária - em relações bruscas e surpreendentes, pode causar estranhamento. Mas as afinidades também são reveladoras.

Chamo a atenção para algumas delas. De início, a mais óbvia, que estaremos discutindo ao longo do ensaio: a centralidade do teatro e da noção de drama no pensamento e na obra dos quatro autores. No campo antropológico, Turner (1986) e Geertz $(1986,1983 a)$ destacam-se pelas formulações originárias - sob inspiração de Wilhelm Dilthey — de uma antropologia da experiência. Daí as afinidades de ambos com Benjamin (1999b, 1985d), em cujos escritos uma noção de experiência aparece como um ponto de in- 
flexão. Benjamin, por sua vez, encontra em Brecht as manifestações de um abalo: a constatação nos palcos do teatro da natureza insólita da experiência contemporânea.

Alguns contrapontos revelam outras afinidades. A antropologia de Clifford Geertz - na qual se tecem interpretações da cultura a partir de metáforas de texto e histórias de narradores - distingue-se da abordagem de Victor Turner, elaborada na Escola de Manchester em torno de questões de conflito. De modo semelhante, a crítica literária de Walter Benjamin — em que se exploram questões de história e narração - estabelece, nos limites da hermenêutica, um contraponto fecundo com a dramaturgia de Brecht, comparativamente mais sociológica e menos interessada na audição de vozes emudecidas do passado diante dos gemidos que se ouvem no presente.

Observa-se, no campo da antropologia, o movimento dialético de Geertz da hermenêutica de Franz Boas e Wilhelm Dilthey à antropologia social - e, em direção inversa, o de Turner - da antropologia social à hermenêutica. Em termos hegelianos, a tese de um apresenta-se como a antítese do outro. Mas em ambos a noção de ação simbólica de Kenneth Burke (1966) adquire as qualidades de uma síntese.

Também vem de Burke (1945) a noção de dramatismo que inspira não apenas as abordagens de Turner e Geertz na antropologia, mas também na sociologia, o interacionismo simbólico de Erving Goffman. Ao passo, porém, que Goffman (1959) procura analisar o teatro da vida cotidiana, Turner se interessa pelo teatro desse teatro, ou metateatro da vida social. O olhar de Turner dirige-se para os momentos de suspensão de papéis. Na medida em que Geertz encontra na cultura as histórias que pessoas contam sobre si para elas mesmas, sua abordagem aproxima-se à de Turner. Ambos se interessam pelas dimensões extraordinárias do cotidiano e pelos modos como as pessoas significam os seus mundos. Goffman, por sua vez, procura revelar as dimensões cotidianas do extraordinário. Em sua desconfiança em relação às formas de mistificação envolvidas na criação de fachadas pessoais e da própria vida social, a sociologia de Goffman aproxima-se especialmente do teatro de Brecht e, até mesmo, do pensamento benjaminiano. Turner inspira-se na tragédia grega (aristotélica)? Mais próximo a Brecht, Goffman interrompe as sequências do drama, focando a cena. De um lado, uma espécie de teatro do maravilhoso. De outro, a revelação dos bastidores. De um lado, as forças de empatia, a catarse e a emoção. De outro, o distanciamento, com efeitos de choque. A ótica dialética que Benjamin (1985a:33) encontra no surrealismo - que vê o cotidiano como impenetrável e o impenetrável como cotidiano - surge como uma interessante fusão de horizontes. A sua tradução, ou possível des-leitura criativa, no campo da antropologia talvez 
exija um esforço no sentido de se juntarem as perspectivas de Goffman e Turner, tomando como foco um metateatro cotidiano.

Neste ensaio, porém, pretendo me deter sobre um contraponto específico. De um lado, Turner e Geertz, cujos escritos nos levam a pensar possivelmente numa espécie de paradigma do teatro dramático na antropologia e, de outro, duas figuras às margens da antropologia e do teatro dramático Benjamin e Brecht.

O ensaio organiza-se em torno de três alegorias, imagens ou momentos: 1. espelho mágico; 2. estilhaçamento; e 3. lampejos. Como será visto a seguir, o percurso pode sugerir a forma de um rito de passagem insólito: a passagem para uma condição de passagem.

\section{Espelho mágico}

Nosso ponto de saída pode surpreender. Ao invés do movimento que se detecta no modelo de ritos de passagem de Arnold Van Gennep, de acordo com o qual se vai do cotidiano ao extraordinário (ou liminar) e de volta ao cotidiano, evoca-se de início a própria experiência do extraordinário - o espelho mágico. Trata-se de uma das imagens prediletas de Victor Turner (1987b:22). Chama a atenção o momento originário de um percurso: os estudos de Turner sobre rituais e suas formulações do conceito de drama social. As sociedades, diz Turner, produzem deslocamentos com efeitos de paralisia em relação ao fluxo da vida cotidiana. Brincando com o perigo, sacaneiam-se a si mesmas. Em momentos extraordinários, às margens, no límen, elas provocam a suspensão de papéis, com efeitos de estranhamento. Em instantes como esses - de liminaridade e communitas (Turner 1969) as pessoas podem ver-se frente a frente como membros de um mesmo tecido social. Daí, a importância dos dramas sociais, e dos rituais que os suscitam (através de rupturas socialmente instituídas) ou deles emergem (como expressões de uma ação reparadora). No espelho mágico dos rituais, caos transforma-se em cosmos, tornando possível a recriação de universos sociais e simbólicos plenos de sentido.

Turner (1957:91-93) elabora o seu conceito de drama social a partir de uma leitura da tragédia grega - em versão aristotélica. Observa-se o encadeamento: 1. ruptura (breach), 2. crise e intensificação da crise, 3. ação reparadora (redressive action), e 4. desfecho, que se manifesta como solução harmonizadora ou reconhecimento de cisão irreparável. Outra fonte de inspiração de Turner vem de Arnold Van Gennep (1960) e seu modelo para a análise dos ritos de passagem, os quais, por sua vez, são entendidos como 
processos constituídos por três momentos: 1. ritos de separação, 2. ritos de transição, e 3. ritos de reagregação. A experiência de liminaridade refere-se particularmente ao segundo momento.

Considerando-se a relevância de Turner - que se manifesta em escritos posteriores - para a elaboração de uma antropologia da experiência, aqui vai uma primeira inquietação. O que dizer dos elementos não resolvidos da vida social que caem no esquecimento, desaparecem em remoinhos, ou permanecem às margens inclusive dos fluxos poderosos de dramas sociais? Ou da experiência de quem se encontra em meio a um espantoso cotidiano, no qual a exceção é a regra? Haveria no modelo de drama social algo que nos predispusesse a focar elementos estruturalmente arredios apenas na medida em que os mesmos contribuem para revitalizar processos estruturantes?

A segunda inquietação, associada à primeira, tem a ver especificamente com o modo como Victor Turner (1987a, 1986, 1982a) concebe uma antropologia da experiência e uma antropologia da performance. Observa-se, de início, o que Turner tem em mente: não a "mera" experiência, que se caracteriza pela passividade, mas justamente a experiência enquanto processo criativo e marcante. Apoiando-se em Dilthey, Turner (1982a:13) delineia cinco momentos segundo os quais se pode analisar essa segunda modalidade de experiência: 1. um desafio apresenta-se no plano da percepção, colocando a pessoa e seus esquemas de interpretação em estado de risco; 2. imagens do passado são evocadas; 3. emoções associadas a essas imagens são revividas; 4. imagens do passado articulam-se ao presente "numa relação musical", possibilitando a criação do significado; e 5. uma expressão, ou performance, completa e realiza o processo da experiência. Enquanto a etimologia do termo "experiência" tem a ver com a ideia de risco, ou perigo, como Turner (1982a:17, 1986:35) ressalta, a palavra "performance" nos remete ao francês parfournir, "completar", "realizar totalmente" (Turner 1982a:91).

Eis a inquietação. Considerando-se a metáfora de Turner (via Dilthey) referente ao momento em que imagens do passado se articulam ao presente"numa relação musical" — o que dizer de paisagens sonoras carregadas de ruídos? Na antropologia da experiência de Turner, haveria um risco de se abafarem as vozes mais ruidosas do passado? Ou permitir que elas se afundem no esquecimento? O grito subterrâneo que Antonin Artaud (1999:169) buscava no teatro e o riso infernal que Benjamin (1999a:325, 2006:369) ${ }^{2}$ encontrou em Charles Baudelaire teriam lugar nessa antropologia da experiência? Eis um desafio. Como fazer uma antropologia do barulho, ou dos ruídos que escapam de processos de organização do som? Talvez seja preciso encontrar meios de explorar o que poderíamos chamar de "inconsciente sonoro" das paisagens culturais, ou o equivalente auditivo da noção benjaminiana de 
"inconsciente óptico" (Benjamin 1985c:189). Nos limites da hermenêutica, em que fios sonoros que tecem círculos hermenêuticos se energizam em meio a curtos-circuitos, imagens carregadas de tensões interrompem, com efeitos de paralisia, processos de recriação de significados. Talvez estejamos lidando, afinal, não apenas com questões da interpretação do mundo, mas também da constituição de uma vontade para interromper o seu curso.

Uma performance, ou expressão, completa e realiza o processo da experiência? O que dizer, então, do aspecto não-resolvido e inacabado das coisas? Um ponto de interrogação benjaminiano também cutuca essa antropologia da performance: parfournir, "completar", "realizar totalmente"?

Apontamos acima duas inquietações que se referem ao pensamento de Victor Turner. Uma diz respeito ao seu modelo de "drama social", e outra, ao modo como se concebe o processo de recriação do significado. Quanto ao tal modelo, há tempo Clifford Geertz manifestou as suas próprias inquietações. A forma do "drama social" de Turner corre o risco sempre de virar fórmula, um esquema explicativo capaz de dar conta de ritos de passagem tribais, insurreições mexicanas, relações entre Thomas Becket e Henry II, movimentos milenaristas, romarias e carnavais do Caribe: "uma forma para todas as estações" (Geertz 1983:28). Geertz ainda observa: "No entanto esses processos formalmente parecidos têm conteúdos diferentes" (Ibid.:29). Em Geertz encontramos algo que não havíamos visto em Turner: uma antropologia dos gestos, um olhar que se dirige aos detalhes, aos fragmentos. Fazendo uso criativo de uma noção e de um exemplo do filósofo inglês Gilbert Ryle, ele propõe o que seja uma boa etnografia: a capacidade de distinguir um piscar de olhos de uma piscadela marota. Isto ele chama (com Ryle) de "descrição densa" (Geertz 1978a:15-16). "Contrair as pálpebras de propósito, quando existe um código público no qual agir assim significa um sinal conspiratório, é piscar. É tudo que há a respeito: uma partícula de comportamento, um sinal de cultura e — voilà! — um gesto" (Ibid.:16).

Chama a atenção em Geertz (1978b:65) a sua disposição para "descer aos detalhes, além das etiquetas enganadoras". Desconfia-se dos paradigmas da ordem. "[A] coerência não pode ser o principal teste de validade de uma descrição cultural" (1978a:27). Se, por um lado, "os sistemas culturais têm que ter um grau mínimo de coerência, do contrário não os chamaríamos sistemas" e, de fato, "vemos que normalmente eles têm muito mais do que isso", por outro, "não há nada tão coerente como a ilusão de um paranoico ou a estória de um trapaceiro" (Ibid.:28).

Mas tal como nas análises de Turner, que se inspiram na ideia de "drama social", algo também invariavelmente tende a resolver-se nas interpretações de Geertz. As aproximações entre Geertz e Turner são marcantes. Ambos 
focam o metateatro da vida social, os seus momentos reflexivos. A metáfora do "espelho mágico", que se torna recorrente nos escritos de Turner, também evoca a abordagem que Geertz procura desenvolver. A formulação clássica de Geertz (1978c:316) sobre a briga de galos balinesa, "uma leitura balinesa da experiência balinesa, uma estória sobre eles que eles contam a si mesmos" - muito se aproxima da abordagem desenvolvida por Turner em seus escritos posteriores a respeito do modo subjuntivo ("como se") que caracteriza a performance. Uma briga de galos, tal como os momentos de interrupção discutidos por Turner, também nos leva a focar o extraordinário. É isto, diz Geertz (Ibid.:315-16), a sua capacidade de funcionar como "comentário metassocial", que a coloca "à parte no curso ordinário da vida", erguendo-a "do reino dos assuntos práticos cotidianos" e cercando-a "com uma aura de importância maior".

Particularmente nos seus textos mais conhecidos, detecta-se em Geertz o mesmo "desvio" metodológico de Turner: procura-se focar os momentos em que sociedades brincam com o perigo, "desarrumando os contextos semânticos" (1978c:315). "Brincando com fogo" é um dos subtópicos mais sugestivos do texto de Geertz sobre a briga de galos. Em outro texto, a queda do rei morto e das viúvas nas chamas transforma-se em demonstração poderosa do universo social e simbólico que ganha vida em torno do Negara (Geertz 1991:127-152). Aqui, também, somos levados a ver como um cosmos social se recria do caos.

Assim como os carnavais descritos por Victor Turner, os carnavais de Negara também servem para realçar a sobriedade do "centro" e a "loucura" da "periferia".

[A] procissão [que culminava na cremação do rei morto] tinha uma ordem rigorosa: era tão calma e vincada no seu apex e centro como era tumultuosa e agitada na sua base e margens [...] A cena [...] era um pouco um motim de brincadeira uma violência deliberada, mesmo estudada, concebida para realçar uma quietude não menos deliberada e ainda mais estudada, que os imperturbáveis sacerdotes, agnates, viúvas e mortos tributários se esforçavam por estabelecer perto da torre central. A própria torre, o olho dentro do olho desta tempestade forjada, era também uma imagem cósmica (Geertz 1991:150).

Enfim, os dramas que ganham vida nos escritos de Geertz também parecem reproduzir o movimento característico dos rituais de passagem, envolvendo momentos de "separação", "transição" ou "liminaridade" e "reagregação" ou, conforme a versão desdobrada do "drama social": "ruptura", "crise e intensificação da crise", "ação reparadora" e "desfecho". Haveria nos textos de Geertz uma espécie de enquadramento estético semelhante ao 
que encontramos em Turner? Haveria nessa estética algo que poderíamos chamar de um paradigma do teatro dramático? Ou do melodrama?

Creio que a hermenêutica tem afinidades com esse paradigma. Chama a atenção o modo como o intérprete de um texto, ou conjunto de textos, ou ainda da cultura, conforme a antropologia de Geertz, procura focar justamente os detalhes e os fragmentos mais estranhos e refratários ao entendimento. Geertz dirige o seu olhar ao que se apresenta como estranho não apenas aos "de fora", tal como se espelha no olhar estupefato de Helms diante da cremação das viúvas, mas também aos "de dentro", tal como se espelha no olhar horrorizado de um balinês extremamente polido vendo-se sendo visto representado na selvageria de uma briga de galos. "Qualquer forma expressiva atua (quando atua) desarrumando os contextos semânticos..." (Geertz 1978c:315). Trata-se de uma aposta metodológica: quanto maior a obscuridade daquilo que se toma como objeto de investigação, maior a intensidade de uma iluminação final. O procedimento hermenêutico surge como um ato de risco, levando o intérprete a defrontar-se com abismos, nos lugares mais ermos, onde o outro se apresenta em toda a sua estranheza. Porém, justamente desse lugar olhado das coisas, onde as possibilidades de compreensão parecem ser mais remotas e o sentido das coisas mais tênue, procura-se reconstituir o cosmos. De novo, algo aqui nos faz lembrar dos ritos de passagem: a saída para um lugar distante; a experiência de um estranhamento profundo e, finalmente, a volta para o lugar familiar que se ilumina com intensidade maior.

Assim se desenha o conhecido círculo hermenêutico. Um texto opaco carregado de elementos estranhos se apresenta, colocando em risco os esquemas interpretativos do leitor. Uma "crise" se esboça, demandando uma "ação reparadora": procura-se situar os elementos mais estranhos num conjunto articulado de textos, em con-texto, para fins de expor a sua "normalidade" sem reduzir sua especificidade. O "desfecho": uma iluminação final. Procedese assim, diz Darnton (1988:xvii), "passando do texto ao contexto e voltando ao primeiro, até abrir caminho através de um universo mental estranho". Clifford Geertz (1983b:69) esclarece:

Saltando-se em duas direções, para trás e para frente, entre um todo percebido através das partes que o atualizam e as partes concebidas através do todo que as motiva, procuramos transformá-las, através de um tipo de movimento intelectual perpétuo, em explicações uma da outra (tradução minha).

Se o movimento em direção ao contexto evoca uma espécie de ação reparadora, tal como o terceiro momento do modelo estético que inspira a noção de drama de Victor Turner, os três instantes do círculo hermenêutico 
(do texto ao contexto e de volta ao primeiro) sugerem uma espécie de rito de passagem. A relação que se estabelece entre a parte e o todo não deixa de produzir um efeito de cura, revigorando o todo e transformando em som musical os ruídos de elementos arredios. Voltamos ao familiar enriquecidos pela experiência proporcionada por uma visão ou uma audição do todo.

Uma inquietação: o que escapa desse círculo, e o que nele corre riscos de ser suprimido? Cito como exemplo o relato de L. V. Helms da cremação de um rajah e de três de suas "concubinas", reproduzido (e reinterpretado) por Geertz em Negara. A seguir, um trecho de Helms:

O momento supremo chegava. Com passos firmes e medidos as vítimas puseram o pé no palanque fatal; por três vezes ergueram as mãos unidas sobre as cabeças, em cada uma das quais foi colocada uma pomba e, depois, com o corpo ereto, saltaram para o mar flamejante embaixo, enquanto as pombas largaram voo, simbolizando os espíritos em liberação.

Duas das mulheres não demonstraram, mesmo no derradeiro momento, qualquer sinal de medo; olharam uma para a outra, para verem se ambas estavam preparadas e, logo, sem se inclinarem ou hesitarem, mergulharam. A terceira pareceu hesitar e dar o salto com menos resolução; cambaleou por um momento, e depois seguiu as outras, desaparecendo as três sem proferirem um som (Geertz 1991:130-131).

Agora, a mesma cena - desta vez inserida no "círculo hermenêutico":

A cena da pira... a "morte" da serpente pelo sacerdote com a seta florida; a descida do corpo para o caixão na plataforma crematória [...] a queda silenciosa das viúvas nas chamas; a recolha das cinzas para serem levadas para o mar, com o sacerdote avançando lentamente para espalhá-las nas ondas... tudo isto remetia para o mesmo significado - a serenidade do divino transcendendo a fúria do animal. Toda a cerimônia era uma demonstração gigantesca, repetida de mil maneiras com mil imagens, da indestrutibilidade da hierarquia em face das forças niveladoras mais poderosas que o mundo pode reunir - a morte, a anarquia, a paixão, e o fogo. "O rei está aniquilado! Viva o seu rank!" (Geertz 1991:151).

O que aconteceu com o instante em que "a terceira pareceu hesitar" e "cambaleou por um momento"? Ou mesmo com os olhares trocados entre as duas primeiras? Em lugar desses fragmentos temos apenas "a queda silenciosa das viúvas nas chamas" e a conclusão de que "tudo isto remetia para o mesmo significado". Os "círculos hermenêuticos" também produziriam suas "vítimas sacrificiais"? 
Enfim, haveria na hermenêutica uma intencionalidade unificadora, uma predisposição tendente a reconciliar a parte com o todo, e o todo com a parte, de tal modo que ruídos e tropeços corressem riscos de serem suprimidos? Nas histórias sobre eles que eles contam a si mesmos, também não haveria histórias de esquecimento? Os tropeços, como é sabido, podem ser reveladores. Talvez seja sugestivo o fato de Geertz haver focado justamente os senhores do Negara, que unificam o universo social na medida em que se posicionam em seu umbigo. "A arte de governar é uma arte teatral" (Geertz 1991:152). Mas tal teatro tem sua especificidade. Às margens, resistindo aos efeitos de encantamento do teatro do Negara e de seus senhores, encontram-se outros - mencionados de passagem pelo próprio autor (Ibid.:35) — mais afeitos aos caminhos íngremes, descontínuos, fragmentados: os senhores das montanhas.

Chama a atenção as afinidades entre Turner e Geertz. Haveria nestes autores a manifestação de algo que poderíamos chamar de "paradigma do teatro dramático"? No final de um dos seus últimos ensaios, Turner (1986:43) evoca o que seria uma experiência no teatro: "Um senso de harmonia com o universo se evidencia e o planeta inteiro é sentido como uma communitas". Trata-se, acredito, de um teatro do maravilhoso. A dramaturgia social de $\mathrm{Ne}$ gara, o Estado-teatro de Bali descrito por Geertz, não deixa de evocar essa espécie de teatro. Ali também se apresenta um "espelho mágico". Forças do caos transformam-se em cosmos. Em transe uma sociedade se revela. A vida social ganha a força de uma fantasmagoria.

Aquilo que se disse a respeito de Max Reinhardt poderia se aplicar ao Estado balinês: trata-se de um "mago do teatro". Reinhardt escreveu: "Tudo deve ser feito para encontrar o caminho de nossa mais profunda intimidade, o caminho da concentração, da exaltação, da espiritualização" (apud Bornheim 1992:116). Hofmannsthal, que fazia teatro à maneira de Reinhardt, escreveu: "Não esqueçamos jamais que o palco nada é, e é mesmo pior do que o nada, se não for realmente maravilhoso. Ele deve ser o sonho dos sonhos" (apud Ibid.:117-118). Num clima como este, o teatro de Brecht funciona como um estalo.

Se "a arte de governar é uma arte teatral", como disse Geertz a respeito de Negara, Brecht, por sua vez, quer propor o contrateatro - um taetro, como ele mesmo diz. Passemos agora à nossa segunda alegoria.

\section{Estilhaçamento}

Como quem inicia um rito de passagem insólito, nós nos vimos, no primeiro momento, em lugar carregado de aura, diante de espelhos mágicos. Ali, o 
extraordinário se apresenta de forma estranha, como ponto de partida. Mas o ponto de partida de um rito de passagem não deveria ser o cotidiano? Agora as coisas se invertem. Na passagem para o segundo momento, no qual se esperaria — de acordo com o modelo de Van Gennep — suscitar a experiência do extraordinário, nos vemos sem espelhos mágicos. Também lugar de risco. Motivo de nossas inquietações anteriores. Trata-se da experiência de um cotidiano liminar, ou espantoso cotidiano, em que a exceção é a regra.

Em um texto sobre fenômenos "liminares e liminóides", delineiam-se as ideias de Turner (1982b) a respeito do impacto da Revolução Industrial sobre os gêneros de ação simbólica. Esferas do trabalho ganham autonomia. Como instância complementar ao trabalho, surge a esfera do lazer - que não deixa de se constituir como um setor do mercado. Processos liminares de produção simbólica perdem poder na medida em que, simultaneamente, geram e cedem espaço a múltiplos gêneros de entretenimento - liminóides. As formas de expressão simbólica se dispersam, num movimento de diáspora, acompanhando a fragmentação das relações sociais. Trata-se de um sparagmos, ou desmembramento (Turner 1986:42). Sociedades industrializadas — talvez se possa sugerir - produzem em relação aos processos de significar o mundo uma espécie de revolução copernicana. Provoca-se o descentramento e a fragmentação da atividade de recriação de universos simbólicos.

Chama a atenção um conjunto de afinidades entre a antropologia de Victor Turner e o pensamento de Walter Benjamin. Menciono três: 1. Ambos os autores fazem uma espécie de arqueologia da experiência. Ao explorar os substratos de culturas contemporâneas, Turner encontra a experiência liminar. Benjamin se depara com a grande tradição narrativa, na qual se forma uma experiência coletiva - erfahrung ("do radical fahr - usado ainda no antigo alemão no seu sentido literal de percorrer, de atravessar uma região durante uma viagem") (Gagnebin 1994:66); 2. Turner discute o enfraquecimento da experiência liminar, o sparagmos ou desmembramento das formas de ação simbólica. Benjamin discute o declínio da grande tradição narrativa e, no estilhaçamento da tradição, o empobrecimento da experiência; 3. Em gêneros "liminóides" de ação simbólica Turner descobre fontes do poder liminar. Nas novas formas narrativas Benjamin encontra indícios da grande tradição narrativa: o seu não-acabamento essencial e a abertura às múltiplas possibilidades. Uma experiência com o passado, da qual irrompem esperanças ainda não realizadas.

É possível também indicar diferenças entre os autores. Nas atenções de Turner à noção de drama social, em seus escritos sobre antropologia da performance e da experiência, manifestam-se esperanças de encontrar em gêneros contemporâneos de expressão algo parecido com os espelhos mágicos dos rituais. Ilumina-se, em tais textos, a nostalgia de Turner por uma 
experiência coletiva, vivida em comum, passada de geração em geração, e capaz de recriar um universo social e simbólico pleno de significado. Mesmo ao discutir as dimensões trágicas da experiência contemporânea — o sparagmos de suas formas de ação simbólica - Turner ainda encontra esperanças em espelhos mágicos. Para Benjamin, porém, trata-se não apenas de uma dispersão dos espelhos, mas, de fato, de um estilhaçamento. Espelhos mágicos se partem. E se desfazem ilusões de refazer o espelhão. Em seu lugar, poderíamos dizer, surge uma multiplicidade de fragmentos e estilhaços de espelhos, com efeitos caleidoscópicos, produzindo uma imensa variedade de cambiantes, irrequietas e luminosas imagens. Mas são cacos — nada mais. ${ }^{3}$

Catástrofe da história.

O curso da história como se apresenta sob o conceito da catástrofe não pode dar ao pensador mais ocupação que o caleidoscópio nas mãos de uma criança, para a qual, a cada giro, toda a ordenação sucumbe ante uma nova ordem. Essa imagem tem uma bem fundada razão de ser. Os conceitos dos dominantes foram sempre o espelho graças ao qual se realizava a imagem de uma "ordem". O caleidoscópio deve ser destroçado (Benjamin 2006:384, 1999a:339, 1995a:154) ${ }^{4}$

\section{Piscadelas de caveiras: o barroco e a alegoria}

Benjamin (1992:54-55) encontra no drama barroco alemão (Trauerspiel) semelhanças marcantes com sua própria época: a perda de sentido do mundo, a sua fragmentação, a arbitrariedade das associações, os neologismos. Chama a atenção a leitura benjaminiana da alegoria. Por um lado, o conceito aponta para a falta de sentido das coisas, fragmentação, descontextualização, e arbitrariedade do significado ou de qualquer empreendimento hermenêutico. Por outro lado, mas pelas mesmas razões, ressalta-se a sua polissemia e abertura para os múltiplos significados: "Uma pessoa, um objeto, e uma relação qualquer pode significar absolutamente qualquer outra coisa" (Ibid.:175). "A linguagem é despedaçada para que em seus fragmentos ela adquira um significado alterado e mais intenso" (Ibid.:208). "No campo da intuição alegórica a imagem é um fragmento, uma ruína [...] A falsa aparência de totalidade é destruída. Pois o eidos desaparece, a símile deixa de existir, e o cosmos que ela contém se atrofia" (Ibid.:176). Por isso, tanto pela "desarrumação" quanto pelas possibilidades de criação e capacidade para associações surpreendentes e inéditas, o espaço do barroco pode ser comparado por Benjamin ao esconderijo de mágico, laboratório de alquimista, quarto de criança, local de despejo ou porão (Ibid.:188). ${ }^{5}$ 
No Trauerspiel, Benjamin $(1992: 50,75)$ se depara com uma forma de drama cujas semelhanças com o teatro épico de Brecht se destacam: a minimização da intenção ilusionista, a economia da trama, a indiferença em relação à produção da catarse. Com um gosto por citações de figuras obscuras, Benjamin (Ibid.:75) cita uma crítica de Gervinius: “'‘a progressão das cenas é montada apenas para explicar e dar continuidade aos atos; não se busca um efeito dramático jamais'". Há ainda outra semelhança com Brecht: "As alegorias tornam-se obsoletas porque faz parte de sua natureza produzir o choque" (Benjamin 1992:183). "Não é acidental que a Idade Média e o barroco se deliciassem na justaposição significativa de estátuas de ídolos e ossos dos mortos" (Ibid.:222).

Nos trabalhos de Benjamin o presente europeu do período entre as guerras ganha as feições culturais de "'um tempo de nascimento e um período de transição para uma nova era', definido, por um lado, 'por um colossal estilhaçamento da tradição' e, por outro, pela perspectiva de uma 'renovação da humanidade'" (Osborne 1997:90). "Com o conceito de alegoria, polissêmico, aberto, histórico, hostil a todo gênero de monismo na interpretação da realidade, Benjamin explorou o mundo de Kafka (esse 'código de gestos', como ele genialmente percebeu), da montagem surrealista e da tragédia barroca" (Merquior 1969:110). A essa lista poderíamos acrescentar a poesia de Baudelaire e a tradição exegética da Kabbalah (Scholem 1997). Jeanne Marie Gagnebin (1985:18) escreve sobre a apropriação benjaminiana de Kafka, evocativa de suas interpretações do Trauerspiel:

\begin{abstract}
Poderíamos arriscar um paradoxo e dizer que a obra de Kafka, o maior "narrador" moderno, segundo Benjamin, representa uma "experiência" única: a da perda da experiência, da desagregação da tradição e do desaparecimento do sentido primordial. Kafka conta-nos com uma minúcia extrema, até mesmo com certo humor, ou seja, com uma dose de jovialidade (Heiterkeit), que não temos nenhuma mensagem definitiva para transmitir, que não existe mais uma totalidade de sentidos, mas somente trechos de histórias e de sonhos. Fragmentos esparsos que falam do fim da identidade do sujeito e da univocidade da palavra, indubitavelmente uma ameaça de destruição, mas também - e ao mesmo tempo esperança e possibilidade de novas significações.
\end{abstract}

Benjamin interessou-se especialmente pelo uso que Baudelaire fez da alegoria na época dos grandes projetos de Haussmann de reurbanização de Paris, em meados do século 19. Em meio à "destruição inovadora" do capitalismo, conforme o diagnóstico de Karl Marx e Friedrich Engels (1982:110 apud Berman 1990:93), "todas as relações fixas, imobilizadas, com sua aura 
de ideias e opiniões veneráveis, são descartadas; todas as novas relações, recém-formadas, se tornam obsoletas antes que se ossifiquem. Tudo que é sólido se desmancha no ar, tudo que é sagrado é profanado". Esse clima de "ininterrupta perturbação, interminável incerteza e agitação" (Ibid.) também evoca o barroco do Trauerspiel. Até mesmo as catástrofes são transformadas em lucrativas. Nesse capitalismo industrial emergente, pessoas viram coisas e coisas ganham vida. A sociedade burguesa também é lida sob o signo da caveira. Para a capa de Les fleurs du mal, Baudelaire deu instruções para que se usasse como modelo uma gravura do século 16 de um esqueleto em forma de uma árvore, em cuja sombra cresciam plantas venenosas (BuckMorss 1991:197). "A relação entre mercadorias e seus valores é tão arbitrária quanto a relação entre as coisas e seus significados na emblemática barroca" (Ibid.:179). Porém, Benjamin aponta para a especificidade de Baudelaire:

Interromper o curso do mundo - era esta a vontade maior de Baudelaire, e nesse sentido ele foi além da melancolia passiva dos alegoristas barrocos. A alegoria de Baudelaire - em oposição ao barroco - leva as marcas da raiva necessária para irromper nesse mundo e deixar em ruínas suas estruturas harmoniosas (Benjamin 2006:363, 1999a:318, Benjamin 1995a:160, 164) ${ }^{6}$

Na elaboração de uma antropologia interpretativa, Clifford Geertz (1978a:16) propõe-se a fazer uma "descrição densa" em que seja possível diferenciar um piscar de olhos de uma piscadela marota. Benjamin ainda procura captar piscadelas de caveiras.

\section{"Manuscrito estranho, desbotado...": histórias de esquecimento}

Há uma "afinidade eletiva" entre as "leituras" de Geertz e Benjamin da cultura. Trata-se para o primeiro de ler "um manuscrito estranho, desbotado, cheio de elipses, incoerências, emendas suspeitas e comentários tendenciosos, escrito não com os sinais convencionais do som, mas com exemplos transitórios de comportamento modelado" (Geertz 1978a:20). A não ser por um detalhe, talvez seja esta também a tarefa que Benjamin se propõe. O detalhe, porém, abre uma verdadeira fenda. Em Benjamin, o que se busca não são os "exemplos transitórios de comportamento modelado". Não se buscam os gestos e os detalhes de comportamento para revelar o modelo. Seu olhar dirige-se justamente ao que escapa do modelo. "Arrumar seria aniquilar" (Benjamin 1993:39). Não se procura no manuscrito nem mesmo um modelo e uma coerência fugidia. Procura-se justamente aquilo que um 
modelo tende a ocultar: sua "estranheza", seu "desbotamento" e suas "elipses", "incoerências", "emendas suspeitas" e "comentários tendenciosos". Trata-se, para Benjamin, de revelar aquilo que interrompe a leitura do manuscrito. "Escovando a história a contrapelo" (Benjamin 1985e:225), ele procura "salvar" o "esquecido". Ao invés de descrever o "contexto" que daria sentido aos detalhes e os detalhes que atualizariam o "contexto", Benjamin quer detectar os detalhes que subvertem o "sentido" do texto. Para isso, é preciso arrancá-los do contexto. Para Benjamin, a descrição de um contexto e a escritura de uma narrativa não deixam de ser formas de produzir esquecimento.

Suas perguntas são simples: Como se fixou a narrativa? Como se montou o contexto? Diante de tantas incoerências, emendas suspeitas e comentários tendenciosos, como lhe deram sentido? O que ficou de fora? O que foi esquecido? Para leitores que não se encontram ou se reconhecem no texto, onde estariam suas esperanças senão nas elipses e no próprio desbotamento do manuscrito - senão em tudo o que faz com que ele seja visto justamente com estranheza? Ao invés de descrever o manuscrito e, a partir de exemplos transitórios, o modelo mais ou menos consciente que lhe daria certa coerência, ele procura captar, no inconsciente do texto, os detalhes que irrompem do esquecimento. Para Benjamin, há esperanças não apenas porque os exemplos de comportamento modelado são transitórios, mas também porque se mostra transitório (desbotado) o manuscrito. No entanto, paradoxalmente, é o mesmo manuscrito, em suas elipses, rasuras e silêncios, que vem carregado de esperanças.

Ao analisar uma briga de galos balinesa, Geertz disse que se trata de "uma história sobre eles que eles contam a si mesmos" (Geertz 1978c:315316). Benjamin, por sua vez, estava "fascinado [...] pela distinção que Freud fez entre memória inconsciente e o ato consciente de recordar" (Jameson 1985:55; cf. Benjamin 1995b:106). O segundo, para Freud (1961:49-50), era um modo de destruir ou erradicar o que o primeiro se propusera a preservar. Nos volumes de Em busca do tempo perdido, Marcel Proust (1913) se propõe a contar sua vida nem como história que "realmente" aconteceu, nem como "recordação", mas enquanto história "esquecida" (Buck-Morss 1991:39). Benjamin, que foi um leitor de Proust, busca nas histórias sobre a sociedade que ela conta a si mesma o que foi esquecido.

Como um leitor de Rosenzweig - que ataca em The star of redemption as pretensões de Hegel de alcançar uma visão da totalidade - Benjamin se propõe a evitar "a tentação de sistematizar, ou sacrificar a especificidade do detalhe por alguma arquitetura conceitual abrangente dentro da qual seria inserida" (Jennings 1987:31). Ele se convencera, na verdade, de que os elementos determinantes da condição humana se encontravam "soterrados 
em cada momento do presente em forma dos pensamentos e das criações mais ameaçadas, odiadas e ridicularizadas" (Ibid.:51).

\section{Lampejos}

Chegamos à terceira alegoria de nosso insólito rito de passagem. De acordo com o modelo de Van Gennep, seria este o momento de reagregação. Mas, em nosso caso, intensifica-se a experiência liminar. Somos levados às margens das margens. ${ }^{7}$ Os lampejos que aqui são produzidos não surgem exatamente de espelhos mágicos, mas de lugares de despejo e seus ares putrefatos e gasosos, onde se encontram os estilhaços e os materiais de molduras e armações apodrecidas. Assim se produzem efeitos de estranhamento em relação não apenas ao cotidiano, mas ao extraordinário também. Lampejos vêm carregados de energia. Com efeitos eletrizantes, produzem inervações corporais e efeitos de despertar. Num raio, espelhos mágicos se transformam em amontoados de cacos.

\section{Duplo deslocamento: às margens das margens}

A respeito do teatro épico de Brecht, Walter Benjamin (1985b:79) escreve:

Para seu público, o palco não se apresenta sob a forma de "tábuas que significam o mundo" (ou seja, como um espaço mágico), e sim como uma sala de exposição, disposta num ângulo favorável. Para seu palco, o público não é mais um agregado de cobaias hipnotizadas, e sim uma assembleia de pessoas interessadas, cujas exigências ele precisa satisfazer.

"Não escondam o palco", diz Brecht (apud Ewen 1967:208-209). "Vocês não são mágicos, mas operários." Trata-se de um duplo deslocamento. Há interessantes afinidades entre Brecht e Turner. Em ambos as atenções se voltam aos efeitos de estranhamento que se produzem às margens. Ambos se interessam pelo metateatro - ou, até mesmo, antiteatro — da vida cotidiana. Porém, em relação à abordagem de Turner, a dramaturgia de Brecht ainda produz um segundo deslocamento, às margens das margens, suscitando efeitos de despertar em relação ao próprio metateatro. Nesse movimento, elementos não-resolvidos da vida cotidiana produzem espanto. Seria o teatro um "espelho mágico"? Brecht procura mostrar inclusive como tais espelhos são produzidos. Eles têm suas oficinas. E viram estilhaços. 
Para captar o duplo deslocamento do teatro de Brecht, talvez seja preciso articular as abordagens de Erving Goffman, que se interessa pelo teatro da vida cotidiana, e de Victor Turner, que procura captar os momentos de interrupção, ou metateatro. Trata-se de um cotidiano metateatro. Nos versos finais da peça A exceção e a regra (Brecht 1994:160), os atores dirigem-se ao público:

No familiar, descubram o insólito.

No cotidiano, desvelem o inexplicável.

Que o que é habitual provoque espanto.

Na regra, descubram o abuso

E sempre que o abuso for encontrado

Procurem o remédio

(Aqui, preferi usar a tradução de Peixoto 1981:60).

Walter Benjamin escreve: "A tradição dos oprimidos nos ensina que o 'estado de exceção' em que vivemos é na verdade a regra geral" (1985e:226).

Tal lição se aprende num lampejo, tal como numa narrativa de Franz Kafka.

Em Kafka, o inquietante não são os objetos nem as ocorrências, mas o fato de que as criaturas reagem a eles descontraidamente, como se estivessem diante de objetos e acontecimentos normais. Não é a circunstância de Gregor Samsa acordar de manhã transformado em barata, mas o fato de não ver nisso nada de surpreendente - a trivialidade do grotesco - que torna a leitura aterrorizante (Anders 1993:19-20).

\section{Duplo estranhamento: iluminação profana}

Configura-se a especificidade de um olhar carnavalizante capaz de suscitar um efeito de estranhamento em relação aos carnavais analisados por Turner e Geertz. Há sobriedade nesse olhar. A "loucura" do carnaval serve apenas para revelar a verdadeira "loucura" do cotidiano. Na peça O Sr. Puntila e seu criado Matti (Brecht 1992:11-120) temos um exemplo: "Bêbado, Puntila é lúcido. Sóbrio, torna-se alienado!" (Ewen 1967:346). Uma "alienação da alienação", busca Brecht (Ibid:203).

Eis uma questão benjaminiana: como produzir um efeito de despertar em relação ao "teatro do maravilhoso"? Quando a "normalidade" e a razão se revelam como estados de delírio, não adianta mobilizar contra o transtorno estabelecido a própria razão alienada. O surrealismo, diz Ben- 
jamin (1985a:32), "mobiliza para a revolução as energias da embriaguez". No estado de embriaguez o surrealismo procura uma percepção lúcida.

Em busca de uma "dialética da embriaguez", Benjamin se detém na "experiência de indivíduos ou grupos marginalizados, formas de experiência que têm sido suprimidas pela razão" (Jennings 1987:86). Trata-se, para Benjamin, de experiências e tipos de conhecimento capazes de produzir "efeitos de distanciamento" em relação a um cotidiano naturalizado. "Não seria cada êxtase em um mundo sobriedade pudica no mundo complementar?" (Benjamin 1985a:25). Ele procura formas de leitura da sociedade, nos limites da experiência racionalizante, associadas a estados alterados da percepção frequentemente restritos aos que vivem às margens: na experiência das crianças, dos insanos, dos embriagados.

As crianças particularmente são "irresistivelmente atraídas pelo resíduo que surge na construção, no trabalho de jardinagem ou doméstico, na costura ou na marcenaria. [...] [Nos produtos residuais], elas menos imitam as obras dos adultos do que põem materiais de espécie muito diferente, através daquilo que com eles aprontam no brinquedo, em uma nova, brusca relação entre si" (Benjamin 1993:18-19).

Em sua percepção do mundo como lugar de irrompimento do novo, a criança "está sempre embriagada" (Benjamin 2006:285, 1999a:239). ${ }^{8}$ Na flanerie de Baudelaire, Benjamin descobre a capacidade de penetrar "a embriaguez religiosa das grandes cidades" (Benjamin 2006:100, 1999a:61). ${ }^{9}$

Em Rua de mão única, num fragmento intitulado "A caminho do planetário", Benjamin (1993:69) escreve: “[...] O trato antigo com o cosmo cumpria-se [...] na embriaguez [...] É o ameaçador descaminho dos modernos considerar essa experiência como irrelevante, como descartável, e deixá-la por conta do indivíduo como devaneio místico em belas noites estreladas".Diante de uma sociedade transfigurada em "segunda natureza", dotada de poderes "jamais imaginados", evocativos da experiência do "maravilhoso", Benjamin descobre no surrealismo um princípio ao mesmo tempo dessensacionalizante e atento às ilusões objetivistas. "De nada nos serve a tentativa patética ou fanática de apontar no enigmático o seu lado enigmático; só devassamos o mistério na medida em que o encontramos no cotidiano, graças a uma ótica dialética que vê o cotidiano como impenetrável e o impenetrável como cotidiano" (Benjamin 1985a:33).

Trata-se de "uma iluminação profana, de inspiração materialista e antropológica" (Ibid.:23). Aqui, como em Kafka, o misterioso se apresenta — mas de forma corriqueira. "O absurdo é apresentado como se fosse evidente, a fim 
de desacreditar o evidente" (Adorno 1992:323). O evidente torna-se absurdo (Osborne 1997:76). "Paradoxalmente, a experiência que se obtém nesse tipo de leitura pouco tem a ver com a riqueza de uma iluminação mística. As faíscas de conhecimento extraordinárias e intermitentes que conseguimos evocam não o êxtase, mas uma aguda percepção de perda e destituição" (Jennings 1987:120).

Dialética da embriaguez. Em lugar das iluminações de um espelho mágico, a lucidez obtida dos seus cacos.

Existe a place du Maroc em Belleville: aquele desolado amontoado de pedras com seus blocos de moradias uniformes, que encontrei numa tarde de domingo, tornouse para mim não apenas o deserto de Marrocos, mas ao mesmo tempo monumento do imperialismo colonial; nele, a visão topográfica se imbricava com a significação alegórica. No entanto, não perdia seu lugar no coração de Belleville. O despertar de uma intuição como essa geralmente é reservada aos embriagados. E de fato os nomes de ruas transformam-se em casos como esses em alucinógenos, que expandem nossa percepção para novas esferas, em múltiplas camadas. Podemos chamar essa força, através da qual eles nos colocam nesse estado, de vertu évocatrice - mas isso diz muito pouco, pois não se trata da associação, mas sim da interpenetração, que é determinante aqui (Benjamin 2006:559, 1999a:518). ${ }^{10}$

Neste registro, uma imagem longínqua do deserto de Marrocos torna-se próxima. Não se trata, porém, de uma experiência do maravilhoso. À revelia da experiência teatral evocada por Turner (1986:43), aqui não se evidencia "um senso de harmonia com o universo". Tampouco "o planeta inteiro é sentido como uma communitas". Ao invés disso, irrompe uma imagem carregada de tensões. O longínquo ilumina o que é próximo enquanto algo insólito. Num instante em que passado e presente relampejam numa constelação, um cortiço parisiense apresenta-se como monumento irônico dos sonhos de expansão colonial.

Tal como Victor Turner, Walter Benjamin se interessa pelos momentos extraordinários da vida social. O olhar de Benjamin, porém, é mais tenso e dialético. Procura-se captar um duplo efeito de estranhamento, em relação ao cotidiano e ao extraordinário também.

\section{Montagem: subterrâneos dos símbolos}

Num artigo sobre Hidalgo e a revolução mexicana, Turner (1974:105) ressalta que Nossa Senhora de Guadalupe, um dos símbolos poderosos 
de uma nacionalidade emergente, é a sucessora de Tonantzin, a mãe dos deuses na cosmologia asteca, cujo culto, anteriormente celebrado no mesmo lugar agora dedicado ao culto de Nossa Senhora de Guadalupe, havia sido eliminado pelos espanhóis. O teatro de Brecht chama a atenção menos pelos símbolos do que pelas imagens e montagens ali produzidas, ao estilo de Eisenstein (1990b:41), carregadas de tensões. Nesses palcos revelam-se os elementos soterrados das paisagens sociais. Símbolos decompõem-se em fragmentos num campo energizado, trazendo à luz os aspectos não resolvidos da vida social, tais como se encontram numa possível "história noturna" (Ginzburg 1991) de Nossa Senhora de Guadalupe.

"Nossas esperanças estão nas contradições", diz Brecht (apud Ewen 1967:174). No Pequeno Organon, ele escreve: "Só tem a vida o que é cheio de contradições" (Brecht 1964, Bornheim 1992:272).

A estética da montagem mobiliza o teatro de Brecht e o pensamento benjaminiano. "O que, então, caracteriza a montagem, e consequentemente sua célula - o plano? A colisão. O conflito de duas peças entre si. O conflito. A colisão. [...] Da colisão de dois fatores determinados nasce um conceito" (Einsenstein 1990b:41).

"A arte", diz Eisenstein (1990a:10), "é o mais sensível dos sismógrafos". Com efeitos de interrupção, procedimentos de montagem podem revelar as tensões subterrâneas que um símbolo tende a ocultar. O comentário de Roland Barthes (1984:194) a respeito do teatro de Brecht é propício: trata-se não tanto de uma semiologia quanto de uma sismologia. Ali se produz um choque, ou abalo da logosfera. ${ }^{11}$

Eis uma questão: a transformação de um corpo em símbolo. Retomando um exemplo anterior, haveria nos pequenos gestos das mulheres do Negara - conforme detectamos no relato de Helms - indícios dos efeitos de estranhamento (Verfremdung) que Brecht buscava no teatro? Não seria, possivelmente, uma hesitação ou tropeço o momento em que uma atriz toma distância da personagem? Na fricção entre um corpo e sua máscara — um lampejo. Nos lampejos de uma memória involuntária em que se detecta a imagem incorporada de Tonantzin não haveria um corpo social friccionando a persona de Nossa Senhora de Guadalupe?

\section{Imagens dialéticas: passado presente}

O que interrompe a encenação do teatro dramático no palco da história é justamente a presença do passado no presente, enquanto algo soterrado. O seu irrompimento demarca uma constelação, justapondo imagens do 
presente e passado, e provocando o susto do reconhecimento. Presente e passado, arrancados do continuum da história, são estranhados. Quem se via num teatro dramático desperta do estado de estupor. Esperanças e promessas soterradas sobem à superfície rachando a crosta de um presente petrificado. Quebra-se o encanto dos mortos sobre os vivos ao mesmo tempo em que aquilo que era tomado como morto e desaparecido mostra a sua cara. O que estava escondido não apenas vem à luz do dia, mas abre as fendas por onde chegam novas fontes de luminosidade.

A sugestão de Eisenstein (1990b:42) é propícia: "Se a montagem deve ser comparada a alguma coisa, então uma legião de trechos de montagem, de planos, deveria ser comparada à série de explosões de um motor de combustão interna". Eis um imperativo benjaminiano: "explodir o continuum da história" (Benjamin 2006:517, 1999a:475, 1985e:230). ${ }^{12}$ Em lampejos, irrompem imagens do passado. "Articular historicamente o passado não significa conhecê-lo 'como ele de fato foi'. Significa apropriar-se de uma reminiscência, tal como ela relampeja no momento de um perigo" (Benjamin 1985e:224-225).

As atenções voltam-se especialmente aos resíduos e aos ruídos capazes de provocarem um abalo - com efeitos de despertar (Benjamin 2006:506, 1999a:464). ${ }^{13}$ Iluminações benjaminianas vêm dos substratos e dos campos submersos. Em lugares onde se reúnem elementos degradados e putrefatos observam-se os lampejos e o brilho efêmero de fogo-fátuo, fosforeando, tremeluzindo.

Benjamin (1985f:103) ${ }^{14}$ evoca a figura do "catador de lixo":

Temos aqui um homem: ele tem de catar pela capital os restos do dia que passou. Tudo o que a grande cidade jogou fora, tudo o que ela perdeu, tudo o que desprezou, tudo o que ela espezinhou — ele registra e coleciona. Coleta e coleciona os anais da desordem, a Cafarnaum da devassidão; separa e seleciona as coisas, fazendo uma seleção inteligente; procede como um avarento em relação a um tesouro, aferrando-se ao entulho que, nas maxilas da deusa da indústria, assumirá a forma de objetos úteis ou agradáveis.

Resíduos revelam uma história do esquecimento. O catador dos "restos do dia que passou" é capaz de fazer despertar a própria memória involuntária da cidade. Seu segredo? A cumplicidade com os objetos por ele colecionados na iminência das "maxilas da deusa da indústria". Resíduos despertam esperanças adormecidas. Também são instrutivos. Diante das ruínas do passado e de suas histórias monumentais, descobre-se que nem mesmo deusas tão poderosas como esta são eternas. Suas maxilas também podem ser despedaçadas. 


\section{Segredo do bricoleur}

Num momento de perigo, imagens do passado articulam-se ao presente (Benjamin 1985e:224). Lampejam imagens de ruínas e resíduos: elementos estruturalmente arredios. Associações surpreendentes, reveladoras, irrompem num teatro cujo palco evoca a paisagem de um depósito de ferro-velho ou canteiro de obras (Benjamin 1993:18). Talvez seja este um dos segredos do bricoleur: os restos e as sobras de estruturas simbólicas que lhe são mais preciosas permanecem às margens de sua obra, escondidos nas dobras da cultura, em testemunho do inacabamento de suas "soluções", configurando um acervo de coisas boas para fazer pensar.

\section{Angelus novus e a "cidade dos espelhos"}

A revolução industrial parecia tornar possível a realização técnica e prática do paraíso. As capitais europeias se transformavam em vitrines reluzentes das promessas e dos sonhos que a nova indústria estimulava. Entre essas, Paris, a "Cidade dos Espelhos", reluzia mais do que qualquer outra. Benjamin descreveu o espetáculo de Paris como "fantasmagoria", um "show" de ilusões ópticas (Buck-Morss 1991:81). "O progresso se transformou na religião do século 19, com as exposições mundiais servindo como santuários, as mercadorias como objetos sagrados, e a 'nova' Paris de Haussmann como Cidade do Vaticano" (Ibid.:90).

Como um "catador de lixo", ou como a criança cuja atenção se volta aos objetos descartados num "canteiro de obras", Benjamin procurava nos registros históricos as "contraimagens que friccionassem duramente a contrapelo do tecido da semântica do progresso" (Buck-Morss 1991:93).

Referindo-se ao projeto premiado do gigantesco "anjo da vitória" celebrando a história dos triunfos militares franceses, apresentado na época das reformas do Porte Maillot - Susan Buck-Morss (1991:94-95) pergunta: "O que poderia ser mais diferente desse monumento ao progresso mítico do que o quadro Angelus Novus de Paul Klee em que Benjamin viu a personificação do 'Anjo da História'?"

Há um quadro de Klee que se chama Angelus Novus. Representa um anjo que parece querer afastar-se de algo que ele encara fixamente. Seus olhos estão escancarados, sua boca dilatada, suas asas abertas. O anjo da história deve ter esse aspecto. Seu rosto está dirigido para o passado. Onde nós vemos uma cadeia de acontecimentos, ele vê uma catástrofe única, que acumula incansa- 
velmente ruína sobre ruína e as dispersa a nossos pés. Ele gostaria de deter-se para acordar os mortos e juntar os fragmentos. Mas uma tempestade sopra do paraíso e prende-se em suas asas com tanta força que ele não pode mais fechálas. Essa tempestade o impele irresistivelmente para o futuro, ao qual ele vira as costas, enquanto o amontoado de ruínas cresce até o céu. Essa tempestade é o que chamamos progresso (Benjamin 1985e:226).

"Na imagem dialética", diz Benjamin, "o passado de uma época particular [...] aparece diante dos olhos (de um momento do presente) em que a humanidade, esfregando os seus olhos, reconhece precisamente esse sonho como um sonho" (Benjamin 2006:506, 1999a:464). ${ }^{15}$ Se Clifford Geertz se propõe a fazer uma "descrição densa" em que seja possível diferenciar um piscar de olhos de uma piscadela marota, Benjamin, que também encontra na sociedade, em sua história e cultura, um texto a ser lido, procura nas imagens dialéticas uma "descrição tensa" - carregada de tensões — capaz de produzir nos próprios leitores um fechar e abrir de olhos, uma espécie de assombro diante de um cotidiano agora estranhado - um despertar.

\section{A Bela Adormecida}

O que dizer ao fim de um insólito rito de passagem - através do qual a experiência de passagem apenas se intensifica? Observa-se o percurso, em forma de montagem. Primeiro, o espelho mágico. Depois, os estilhaços. Em lugares de despejo nos vemos em meio aos cacos - que lampejam. Uma observação: às margens das margens também ocorre uma atividade que, estranhamente, poderia evocar o momento de reagregação previsto por Van Gennep como terceiro momento de um rito de passagem. Trata-se da atividade de um colecionador (Benjamin 2006:237-246, 395; 1999a:203-211, 349; 1985f:103). ${ }^{16}$ Ou catador de lixo. Em suas mãos os cacos se transformam em coisas preciosas.

No pensamento benjaminiano - que não deixa de se apresentar em forma de uma obra fragmentada - assim como no teatro de Brecht lido neste registro, haveria elementos capazes de fazer despertar algumas das possibilidades ainda pouco exploradas no campo da antropologia? Em uma correspondência ao seu amigo Gershom Scholem, Benjamin revela o prefácio que teria escrito para uma possível reapresentação do seu trabalho rejeitado, A origem do drama barroco alemão, à Universidade de Frankfurt. Ele desistiria do plano. O prefácio, porém, que ele contava entre seus melhores escritos, diz o seguinte: 
Gostaria de recontar a história da Bela Adormecida.

Ela dormia em meio aos arbustos de espinhos. E, após tantos e tantos anos, ela acordou.

Mas não com o beijo de um príncipe feliz.

O cozinheiro a acordou quando deu na jovem cozinheira um tabefe nos ouvidos que ressoou pelo castelo, zunindo com a energia represada de tantos anos.

Uma linda criança dorme atrás da cerca viva espinhosa das páginas que seguem.

Mas não deixem que qualquer príncipe de fortuna trajado no equipamento deslumbrante do conhecimento chegue perto. Pois no momento do beijo de núpcias, ela pode mordê-lo [...] (apud Buck-Morss 1991:22).

Creio que os cadernos de campo de antropólogos, nos quais se registram imagens e falas que pertencem a um inconsciente acadêmico e social, também podem ser comparados à criança adormecida de Benjamin. Resta ver se é possível fazê-la despertar.

Recebido em 15 de dezembro de 2008

Aprovado em 22 de setembro de 2009

John Dawsey é professor titular do Departamento de Antropologia — USP. E-mail: < johndaws@usp.br>

\section{Notas}

Agradeço à Fundação de Amparo à Pesquisa do Estado de São Paulo (Fapesp) e ao Conselho Nacional de Desenvolvimento Científico e Tecnológico (CNPq) por apoios recebidos para o desenvolvimento desta pesquisa.

${ }^{1}$ Em uma série de trabalhos, Michael Taussig vem explorando as possibilidades de um enfoque benjaminiano e maneiras de se articular o teatro épico de Brecht à prática da etnografia. Cf. Taussig 1980, 1986, 1992, 1993, 1997, 1999, 2004, 2006.

${ }^{2}$ Cf. Arquivo J53a, 4 (Benjamin 1999a, 2006).

${ }^{3}$ Em "Experiência e pobreza", Benjamin (1999b) discute a extensão de nossa perda. Jennings (1987:119-120) comenta: "Apenas o reconhecimento pleno da extensão de nossa perda pode nos levar a agir". 
${ }^{4}$ Cf. Arquivo J61a, 2 (Benjamin 1999a, 2006).

${ }^{5}$ Em "Rua de mão única", Benjamin (1993:39) fala das gavetas de crianças: "'Arrumar' significaria aniquilar".

${ }^{6}$ Cf. Arquivo J50, 2 (Benjamin 1999a, 2006).

${ }^{7}$ Creio que esta expressão pode evocar, sob signo benjaminiano, alguns dos fenômenos liminóides discutidos por Turner. Em relação às formas liminares, as liminóides evidenciam duas características que merecem atenção especial: 1. elas ocorrem às margens dos processos centrais de produção social (nesse sentido elas são menos "sérias"); e 2. elas podem ser mais criativas (e, até mesmo, subversivas) (Turner 1982b:53-55).

${ }^{8}$ Cf. Arquivo J7, 1 (Benjamin 1999a, 2006).

${ }^{9}$ Cf. Arquivo A13 (Benjamin 1999a, 2006).

${ }^{10}$ Cf. Arquivo P1a, 2 (Benjamin 1999a, 2006).

${ }^{11}$ Esta citação de Barthes também aparece em Taussig (1992:150).

${ }^{12}$ Cf. Arquivo N10a, 1 (Benjamin 1999a, 2006).

${ }^{13}$ Cf. Arquivo N4, 3 (Benjamin 1999a, 2006).

${ }^{14}$ Cf. Arquivo J68, 4 (Benjamin 1999a:349, 2006:395).

${ }^{15}$ Cf. Arquivo N4, 1 (Benjamin 1999a, 2006).

${ }^{16}$ Cf. Arquivos H1, 1 - H5, 1; J68, 4 (Benjamin 1999a, 2006). 


\section{Referências bibliográficas}

ADORNO, Theodor W. 1998. "Caracterização de Walter Benjamin". In: Prismas: crítica cultural e sociedade. São Paulo: Ática. pp. 223-238. 1992. "Benjamin's Einbahnstrasse". In: Notes to literature. vol. 2. New York: Columbia University Press. pp. 322-327.

ANDERS, Gunter. 1993. Kafka: pró e contra. Os autos do processo. São Paulo: Perspectiva.

ARTAUD, Antonin. 1999. O teatro e seu duplo. São Paulo: Martins Fontes.

BARTHES, Roland. 1990. “Diderot, Brecht, Eisenstein". In: O óbvio e o obtuso: ensaios críticos. Rio de Janeiro: Nova Fronteira. pp. 85-92.

. 1984. "Brecht e o discurso: contribuição para o estudo da discursividade". In: O rumor da língua. Lisboa: Edições 70. pp. 193-200.

BENJAMIN, Walter. 2006. Passagens. Org. Willi Bolle. Belo Horizonte/ São Paulo: Editora UFMG/ Imprensa Oficial do Estado de São Paulo. - 1999a. The Arcades Project. Cambridge/ London: The Belknap Press of Harvard University Press.

. 1999b. "Experience and poverty". In: Selected writings. vol. 2 - 1927-1934. Cambridge/London: The Belknap Press of Harvard University Press. pp. 731-736. . 1995a. "Parque central". In: Obras escolhidas III: Charles Baudelaire - Um lírico no auge do capitalismo. São Paulo: Brasiliense. pp. 151-184. - 1995b. "Sobre alguns temas em Baudelaire". In: Obras escolhidas III: Charles Baudelaire - Um lírico no auge do capitalismo. São Paulo: Brasiliense. pp. 103-150. . 1993. "Rua de mão única". In: Obras escolhidas II: rua de mão única. São Paulo: Brasiliense. pp. 9-70.
- 1992. The origin of german tragic drama. London/New York: Verso. - 1985a. "O surrealismo: o último instantâneo da inteligência europeia". In: Obras escolhidas I: magia e técnica, arte e política. São Paulo: Brasiliense. pp. 21-35. . 1985b. "Que é o teatro épico? Um estudo sobre Brecht". In: Obras escolhidas I: magia e técnica, arte e política. São Paulo: Brasiliense. pp. 78-90. . 1985c. "A obra de arte na era da reprodutibilidade técnica". In: Obras escolhidas I: magia e técnica, arte e política. São Paulo: Brasiliense. pp. 165-196. . 1985d. "O narrador: considerações sobre a obra de Nikolai Leskov". In: Obras escolhidas I: magia e técnica, arte e política. São Paulo: Brasiliense. pp. 197-221. . 1985e. "Sobre o conceito da história". In: Obras escolhidas I: magia e técnica, arte e política. São Paulo: Brasiliense. pp. 222-232.

- 1985f. "A Paris do Segundo Império em Baudelaire". In: F. R. Kothe (org.), Walter Benjamin. São Paulo: Ática. pp. 44-122.

BERMAN, Marshall. 1990. Tudo que é sólido desmancha no ar: a aventura da Modernidade. São Paulo: Companhia das Letras.

BORNHEIM, Gerd. 1992. Brecht: a estética do teatro. São Paulo: Graal.

BRECHT, Bertolt. 1994. "A exceção e a regra". In: Teatro completo 4 . Rio de Janeiro: Paz e Terra. pp. 129-160. - 1992. "O Sr. Puntila e seu criado Matti". In: Teatro completo 8. Rio de Janeiro: Paz e Terra. pp. 11-120. . 1964. "A short organum for the theatre". In: J. Willet (org), Brecht on theatre: the development of an aesthetic. New York: Hill and Wang. pp. 179-208. 
BUCK-MORSS, Susan. 1991. The dialectics of seeing: Walter Benjamin and the Arcades Project. Cambridge, Massachusetts/London, England: MIT Press.

BURKE, Kenneth. 1966. Language as symbolic action. Berkeley/Los Angeles/London: University of California Press.

- 1945. A grammar of motives. Berkeley/Los Angeles/London: University of California Press.

DARNTON, Robert. 1988. O grande massacre de gatos. Rio de Janeiro: Graal.

EISENSTEIN, Sergei. 1990a. O sentido do filme. Rio de Janeiro: Jorge Zahar. - 1990b. A forma do filme. Rio de Janeiro: Jorge Zahar.

EWEN, Frederic. 1967. Bertolt Brecht: sua vida, sua arte, seu tempo. São Paulo: Editora Globo.

FREUD, Sigmund. 1961. Beyond the pleasure principle. New York/London: W. W. Norton \& Company.

GAGNEBIN, Jeanne Marie. 1994. História e narração em W. Benjamin. São Paulo: Perspectiva/FAPESP/Editora da Unicamp.

- 1985. "Prefácio". In: W. Benjamin, Obras escolhidas: magia e técnica, arte e política. São Paulo: Brasiliense. pp. 7-20.

GEERTZ, Clifford. 1991. Negara: o Estado teatro no século XIX. Lisboa: Difel. - 1986. "Making experience, authoring selves". In: V. Turner \& E. M. Bruner (orgs.), The anthropology of experience. Urbana/Chicago: University of Illinois Press. pp. 373-380. - 1983a. "Blurred genres: the refiguration of social thought". In: Local knowledge. New York: Basic Books. pp. 19-35.

- 1983b. "'From the native's point of view': on the nature of anthropological understanding". In: Local knowledge. New York: Basic Books. pp. 55-72.

. 1978a. "Uma descrição densa: por uma teoria interpretativa da cultura". In: A interpretação das culturas. Rio de Janeiro: Zahar. pp. 13-44. . 1978b. "O impacto do conceito de cultura sobre o conceito de homem". In: A interpretação das culturas. Rio de Janeiro: Zahar. pp. 45-66.

. 1978c. "Um jogo absorvente: notas sobre a briga de galos balinesa". In: A interpretação das culturas. Rio de Janeiro: Zahar. pp. 278-321.

GINZBURG, Carlo. 1991. História noturna: decifrando o Sabá. São Paulo: Companhia das Letras.

GOFFMAN, Erving. 1959. The presentation of self in everyday life. Garden City, New York: Doubleday Anchor Books.

JAMESON, Fredric. 1985. "Versões de uma hermenêutica marxista: Walter Benjamin ou nostalgia". In: F. Jameson, Marxismo e forma: teorias dialéticas da literatura no século XX. São Paulo: Hucitec. pp. 53-70.

JENNINGS, Michael W. 1987. Dialectical images: Walter Benjamin's theory of literary criticism. Ithaca/London: Cornell University Press.

MARX, Karl \& ENGELS, Friedrich. 1982. "O manifesto do Partido Comunista". In: Obras escolhidas. Tomo I. Lisboa: Edições Avante. pp. 95-136.

MERQUIOR, José Guilherme. 1969. Arte e sociedade em Marcuse, Adorno e Benjamin: ensaio crítico sobre a Escola Neohegeliana de Frankfurt. Rio de Janeiro: Tempo Brasileiro.

OSBORNE, Peter. 1997. "Vitórias de pequena escala, derrotas de grande escala: a política do tempo de Walter Benjamin". In: A. Benjamin e P. Osborne (orgs.), A filosofia de Walter Benjamin: destruição e experiência. Rio de Janeiro: Jorge Zahar. pp. 72-121. 
PEIXOTO, Fernando. 1981. Brecht: uma introdução ao teatro dialético. Rio de Janeiro: Paz e Terra.

PROUST, Marcel. 1913. À la recherche du temps perdu. Paris: Plêiade.

SCHOLEM, Gershom. 1997. A cabala e seu simbolismo. São Paulo: Perspectiva.

TAUSSIG, Michael. 2006. Walter Benjamin's grave. Chicago/London: The University of Chicago Press. . 2004. My cocaine museum. Chicago/ London: The University of Chicago Press.

1999. Defacement: public secrecy and the labor of the negative. Stanford, California: Stanford University Press. 1997. The magic of the state. New York/London: Routledge. - 1993. Mimesis and alterity. New York/London: Routledge. . 1992. The nervous system. New York/ London: Routledge. -1986. Shamanism, colonialism, and the wild man: a study in terror and healing . Chicago/London: The University of Chicago Press.

_ 1980. The devil and commodity fetishism in South America. Chapel Hill: University of North Carolina Press.

TURNER, Victor. 1987a. The anthropology of performance. New York: PAJ Publications.

. 1987b. "Images and reflections: ritual, drama, carnival, film and spectacle in cultural performance". In: The anthropology of performance. New York: PAJ Publications. pp. 21-32.

. 1986. "Dewey, Dilthey, and drama: an essay in the anthropology of experience". In: V. Turner \& E. M. Bruner (orgs), The anthropology of experience. Urbana/Chicago: University of Illinois Press. pp. 33-44.

1982a. From ritual to theatre: the human seriousness of play. New York: PAJ Publications.
- 1982b. "Liminal to liminoid, in play, flow, and ritual: an essay in comparative symbology". In: From ritual to theatre: the human seriousness of play. New York: PAJ Publications. pp. 20-60.

- 1974. Dramas, fields, and metaphors: symbolic action in human society. Ithaca/London: Cornell University Press.

- 1969. The ritual process: structure and anti-structure. Ithaca, New York: Cornell University Press.

- 1957. Schism and continuity in an african society: a study of Ndembu village life. Oxford e Washington, D.C.: BERG.

VAN GENNEP, Arnold. 1960. The rites of passage. Chicago: The University of Chicago Press. 


\section{Resumo}

Este ensaio se apresenta como um canteiro de obras benjaminiano. A justaposição de figuras aparentemente distantes em relações bruscas e surpreendentes talvez provoque estranhamento. Mas as afinidades são reveladoras. Nos remoinhos dos estudos de Michael Taussig, busco uma composição teórica em contraponto: de um lado, Victor Turner e Clifford Geertz, cujos escritos nos levam a pensar possivelmente numa espécie de paradigma do teatro dramático na antropologia e, de outro, duas figuras às margens da antropologia e do teatro dramático Walter Benjamin e Bertolt Brecht. A força gravitacional do ensaio encontra-se nessas margens, especialmente na obra fragmentada de Benjamin. Trata-se de um ensaio por uma antropologia benjaminiana, que se organiza em torno de três alegorias: 1. espelho mágico; 2 . estilhaçamento; e 3. lampejos. O percurso não deixa de sugerir a forma de um rito de passagem insólito: a passagem para uma condição de passagem.

Palavras-chave Walter Benjamin, Bertolt Brecht, Victor Turner, Clifford Geertz

\section{Abstract}

This essay is presented as a Benjaminian work site. The juxtaposition of apparently distant figures in brusque and surprising relations may well cause puzzlement. But the affinities are revealing. In the whirlpools of Michael Taussig's studies, I search for a theoretical composition in counterpoint: on one side, Victor Turner and Clifford Geertz, whose writings possibly lead us to think of a kind of paradigm of the dramatic theatre in anthropology, and, on the other, two figures on the margins of anthropology and the dramatic theatre - Walter Benjamin and Bertolt Brecht. The essay's gravitational force is located on these margins, especially the fragmented work of Benjamin. In short, this is an essay towards a Benjaminian anthropology, organized around three allegories: (1) magic mirror; (2) shattering; and (3) flashes of light. In some ways, the journey suggests the form of an unusual rite of passage: the passage towards a passing condition.

Key words Walter Benjamin, Bertolt Brecht, Victor Turner, Clifford Geertz 